\title{
Personal Injury Incident Analysis and Risk Prevention during Tanker Shipping Voyages
}

\author{
Qingji Zhou, Hong Xu, and Yiik Diew Wong
}

\begin{abstract}
It is well-recognized that shipping and ship management companies face lots of potential hazards and recurring accidents in relation to occupational health and safety for their crew during the daily operations. In this study, personal injury incidents are analyzed, and factors that are strongly associated with personal injury incidents are evaluated. The results show that the contributory factors that have strong relationship with personal injury occurrences are injured seafarer's nationality, length of time on board vessel, location along voyage, trading region, and type of on-board operation. These contributory factors are examined in terms of direct factors, indirect factors, and root factors. The predominant direct factors associated with personal injury incidents are unsafe acts such as improper method/procedure and unsafe conditions such as workplace restrictions. Human factors such as inattention and haste are identified to be indirectly associated with a large number of personal injury incidents. Among the root factors, incompatible procedure is the most important factor associated with personal injury incidents. Herein, risk control measures are proposed to improve safety in tanker shipping.
\end{abstract}

Index Terms-Personal injury incident, tanker shipping industry, contributory factor, Risk analysis and prevention.

\section{INTRODUCTION}

World oil demand has been increasing rapidly in recent years. Much of the oil is transported by oil tanker which is a specialized ship designed to transport oil from offshore oil fields to onshore refineries. Also, oil tankers are often used as an alternative to pipelines in remote locations with harsh climates or in deep-water area. A review of maritime transport [1] showed that, from 1970 to 2015 , international tanker cargo trade increased from 1,440 million tons to 2,947 million tons. Various kinds of accidents occur at sea arising from crew's fatigue, shipboard fire \& explosion, etc. Some notable examples of maritime accidents are the explosion of the Piper Alpha platform in 1988, the grounding of Exxon Valdez VLCC in 1989, and the explosion of Deepwater Horizon drilling rig in 2010. The enormity of losses from these accidents aroused wide attention all over the world.

In reality, shipping and ship management companies face a lot of challenges in relation to managing occupational health and safety of seafarers, vessel safety and security, and

Manuscript received January 20, 2017; revised May 20, 2017.

Qingji Zhou is with Maritime Institute, NTU, Nanyang Technological University, Singapore (e-mail: qjzhou@ntu.edu.sg).

Hong $\mathrm{Xu}$ is with School of Humanities and Social Sciences, Nanyang Technological University, Singapore (e-mail: xuhong@ntu.edu.sg).

Yiik Diew Wong is with Centre for Infrastructure Systems, School of Civil and Environmental Engineering, Nanyang Technological University, Singapore (e-mail: cydwong@ntu.edu.sg). environmental risks in daily operations. As for personal risk on board oil tankers, existing research is concentrated on crew's response to motion of the ships, fatigue of crew on board the ships, toxic risk especially during tank cleaning and loading and unloading of gasoline [2], [3].

The shipping industry has always been one in which seafarers' relative risks of ill health, injury and death have been considerable [4]. Collins et al. [5] researched on fatigue, health and incident rates of employees engaged in exploration, production and supporting roles in the offshore oil industry. Smith et al. [6] investigated seafarers' fatigue on ships in the offshore oil industry where long working hours, varying shift patterns, reduced manning and problems with vessel's motion and noise were often noted. Also, a questionnaire was designed that encompassed all aspects of an offshore worker's in-service life to assess the nature of tours of duty, work and rest patterns, fatigue and sleep, health-related behaviors and general health and well-being. Smith et al. also carried out a research program to investigate seafarers' fatigue in order to predict the worst case scenario for fatigue, health and injury; to develop best practice recommendations appropriate to ship type and trade; and to produce advice packages for seafarers, regulators and policy makers.

Haward et al. [7] studied crew's responses to motions of floating production and storage offshore vessel at a fixed location to identify the crew's difficulties and symptoms associated with ships' motion. They concluded that crew's difficulties increased on days when ships' motions increased, with some activities and responses particularly influenced by vessel's motions.

Allen et al. [8] summarized the fatigue risk factors of seafarers, which included circadian rhythms, working patterns and shift schedules, noise and motion, sleep and other risk factors. Wellens [9] interviewed seafarers about their collision experience and found that fatigue is a potentially important contributory factor to collision. Jensen et al. [10] conducted a questionnaire study across 11 countries with 6,461 seafarers looking at factors associated with injury in their latest tour of duty. Most notably no evidence was found on the association between long working hours and increased injury likelihood, although a number of other significant results were shown. Those reporting significantly higher incidence of injury include non-officers compared to officers, younger seafarers compared with older seafarers and those working shorter tours of duty.

Crews on chemical and product tankers may come into contact with toxic cargoes, especially during tank cleaning, and loading and unloading of gasoline. High benzene concentrations up to $100 \mathrm{ppm}$ have been measured. Furthermore, the engine room crew is exposed to a variety of 
exposures with possible harm to health, such as polycyclic aromatic hydrocarbons. Moen et al. [11] found traces of degraded hydrocarbon products and other chemicals in the urine of ship engineers. The clinical importance of these findings, however, is still unclear. Toxic substances can accumulate in accommodation aboard tankers and also affect the indoor climate in some cases, and possibly the health of the crew and their work performance subsequently.

In fact, crew working on board the tankers not only face the hazards associated with motion of the ships, fatigue on board the ships, toxic risk especially during tank cleaning, loading and unloading of gasoline, they also sustain various kinds of potential personal injuries during different kinds of operations They get hurt on various parts of the body, resulting in fatality in some cases. Personal injury incidents are directly associated with unsafe conditions and unsafe acts. Examples of unsafe conditions include poor housekeeping, inadequate guards/ barriers, defective tool/ equipment/ material, and so on. Examples of unsafe acts include horseplay, boisterous behavior, failing to use PPE (personal protective equipment), unlawful acts, and so on. Herein, shipping incidents analysis is quite a common topic of research which has attracted the attention of research scholars. Such research studies can help to shed insights on the safety of the shipping industry.

The focus of this study is to analyze personal injury incidents recorded by an international tanker shipping company, find out the factors that have strong relationship with the incidents, categorize the contributory factors as direct factors, indirect factors and root factors, and propose risk control measures to make shipping voyages safer and more reliable.

\section{PERSONAL InJURy INCIDENT DATA ANALYSIS}

\section{A. Personal Injury Incident Data}

Upon examining the incident reports (from 2008 to July 2015 ) of a large global owner-operator of tankers with operations in over 10 countries, around 260 personal injury incidents were recorded during daily on-board operations. The seafarers usually get hurt in different parts of the body, including abdomen, arm, back, ear, eye, face, finger, foot, groin, hand, head, leg, neck, shoulder and others. The reasons for personal injuries include slip, trip or fall on same level; hit by moving/ flying/ falling object; hitting/ hit by object; injured by animal/ insect; caught in between objects; contact with moving machinery; contact with machined material; contact with electricity; contact with harmful substance; contact with hot surface/ fire; exposed to harmful substance; trapped by something collapsing; illness, and other situations.

The consequences of personal injury on board tankers include First Aid Case (FAC), Lost Time Injury (LTI), Medical Treatment Case (MTC) and Restricted Workday Case (RWC), among which the FAC made up almost half $(48 \%)$ of the incidents. FAC covers any one-time treatment and subsequent observation or minor injuries such as bruises, scratches, cuts, burns, or splinters. LTI refers to an injury in which the individual is unable to carry out any of his duties or to return to work on a scheduled work shift on the day of the injury unless caused by delays in getting medical treatment ashore. MTC refers to any work-related loss of consciousness (unless due to ill health), injury or illness requiring more than first aid treatment. RWC covers an injury in which the individual is unable to perform all normal work functions after the day on which the injury occurred. Meanwhile, the seafarers may get ill during their voyages. The personal injury incidents distributed by injury category are shown in Fig. 1.

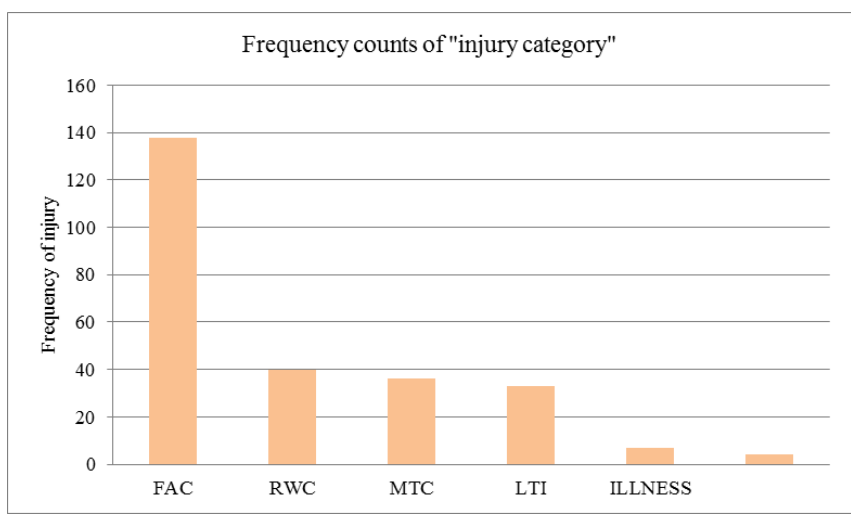

Fig. 1. Personal injury incidents by injury category.

Personal injury incidents distributed by type of operation are shown in Fig. 2. The personal injury incidents occurred mostly during general deck maintenance, machinery haul/ repair/ test, routine work and mooring operation. In addition, there were 39 incidents for other types of operation.

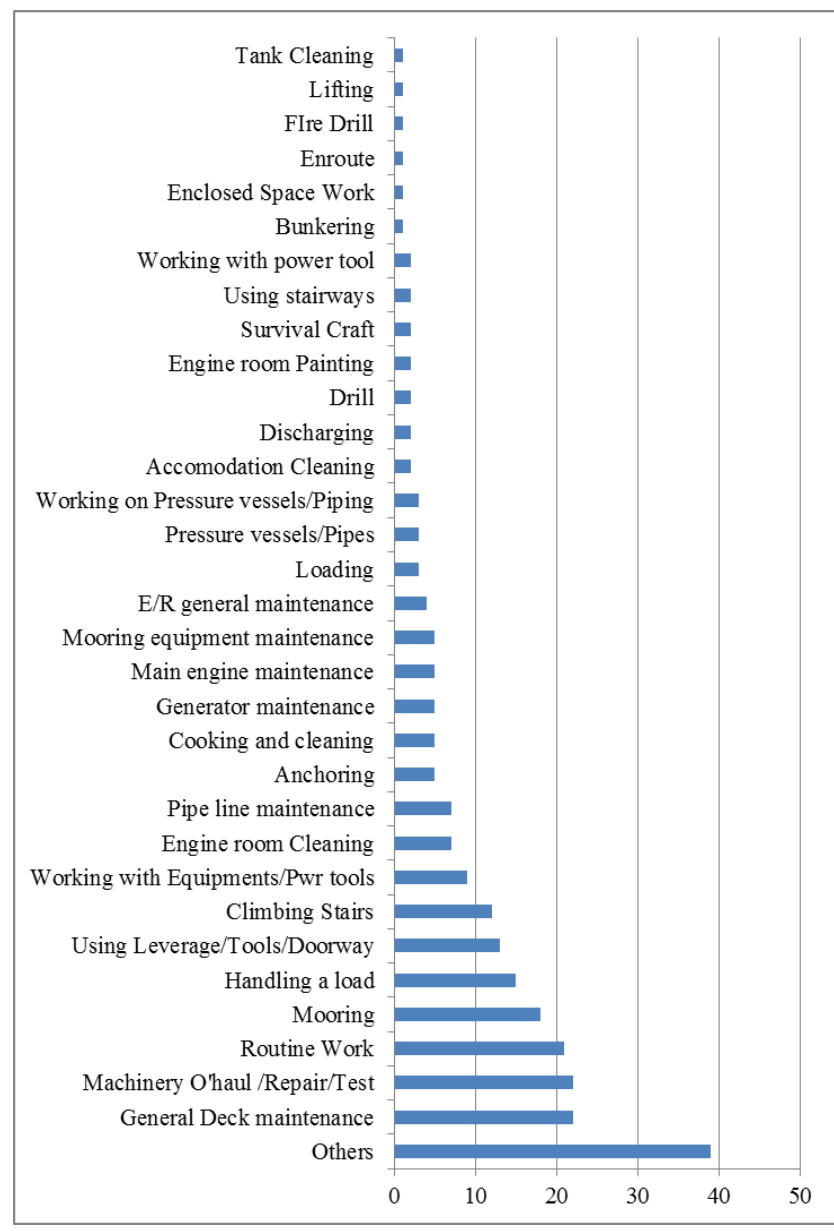

Fig. 2. Personal injury incidents by type of operation.

The vessel types in the tanker fleets were: Aframax 
(AFRA), Very Large Crude Carrier (VLCC), Panamax (PANA), Suezmax (SUEZ), Medium Range (MR), Dynamic Positioning Shuttle Tanker (DPST), Long Range 2 (LR2) and HANDY. The distribution of personal injuries by vessel type is shown in Fig. 3.

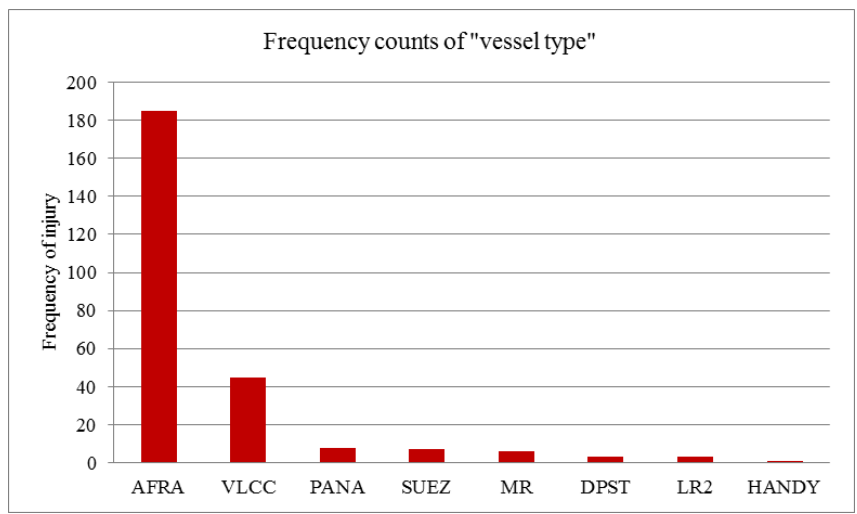

Fig. 3. Personal injury incidents by vessel type.

For on-board seafarers, the largest injury groups by nationality were: $38 \%$ Indian; 26\% Malaysian; and $15 \%$ Filipino. The distribution is shown in Fig. 4.

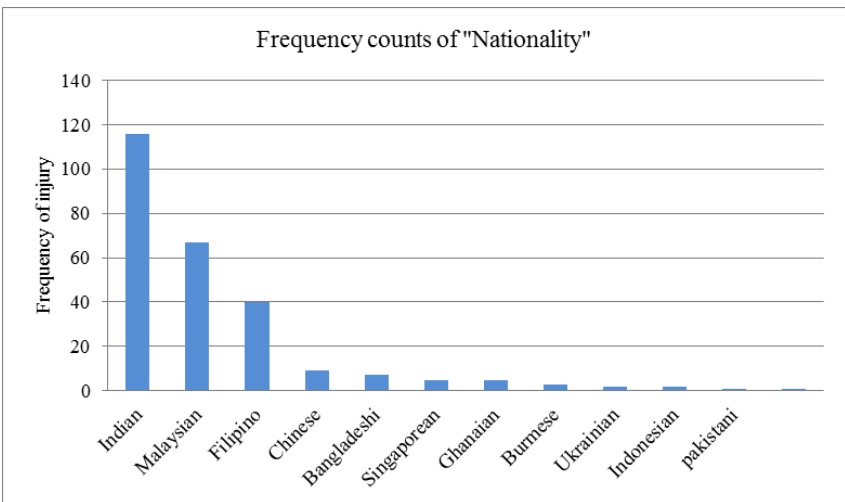

Fig. 4. Personal injury incidents by nationality.

The distribution of personal injury by place on board vessel is shown in Fig. 5. The injury usually occurred at the engine room, main deck, and accommodation.

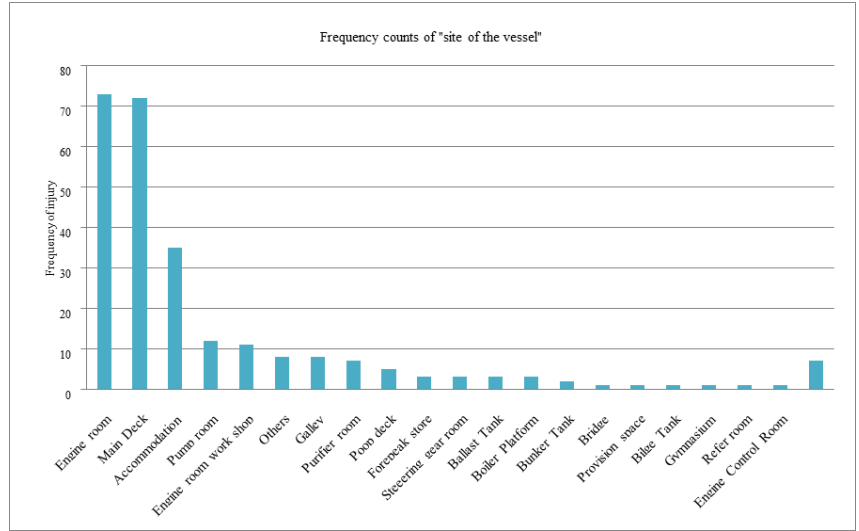

Fig. 5. Personal injury incidents by place on board vessel.

The length of time on board (TOB) vessel may result in boredom of the seafarers. Interestingly, seafarers usually got hurt during the first month of the voyage, as shown in Fig. 6.

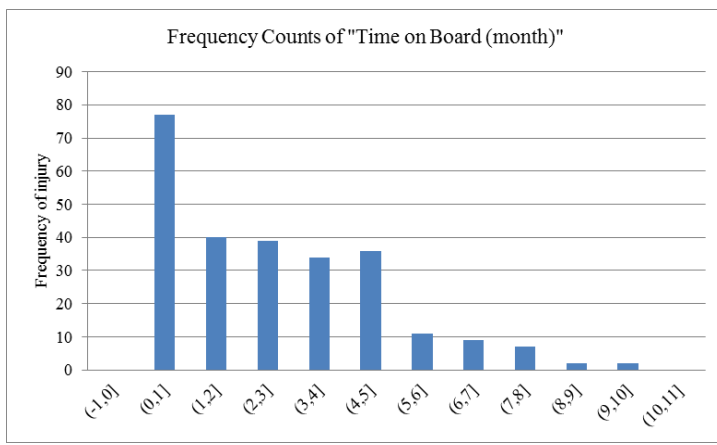

Fig. 6. Personal injury incidents by time on board vessel (month).

The duration of service of the injured person with the company ('time in company') when the personal injury occurred is shown in Fig. 7. The personal injury usually occurred in the first few years of service with the company.

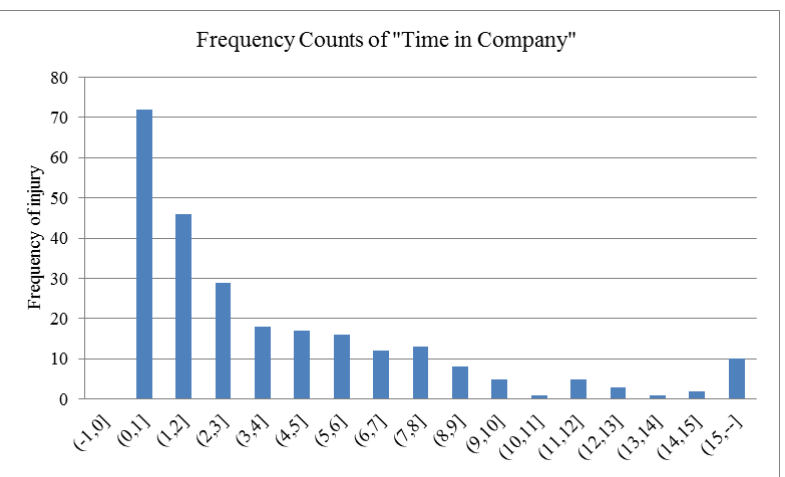

Fig. 7. Personal injury incidents by time in company (years).

As shown in Fig. 8, personal injury incidents on tankers usually occurred at sea, anchorage place and in port, making up about $43 \%, 26 \%$ and $24 \%$, respectively according to the records.

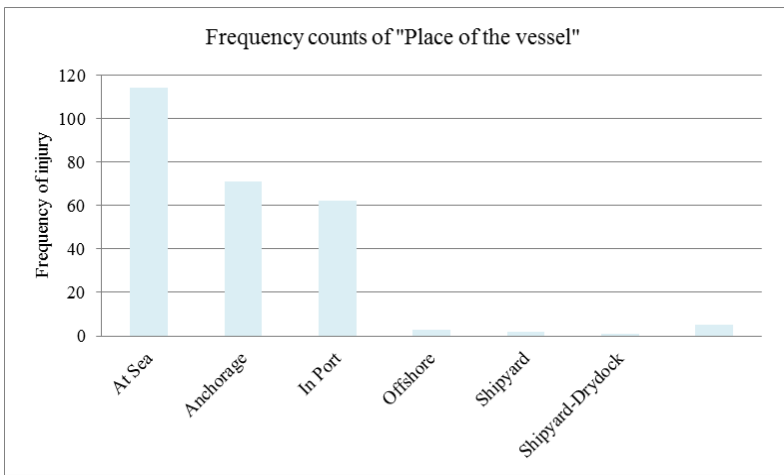

Fig. 8. Personal injury incidents by vessel location along voyage.

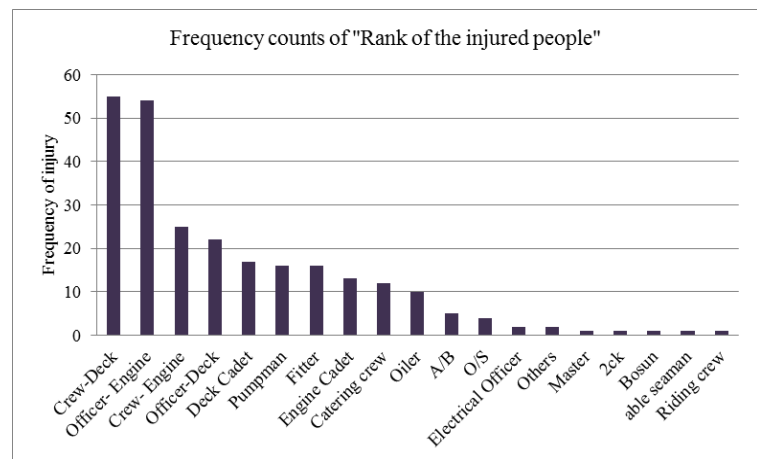

Fig. 9. Personal injury incidents by crew's rank. 
The distribution of personal injury by rank of crew-deck, officer-engine, crew-engine and officer-deck is shown in Fig. 9. This indirectly suggests that the nature of injury would be associated with the place and operation on board.

Personal injury incidents distributed by injured person's age are shown in Fig. 10. The age of the seafarers between 20 and 35 years was the most common group.

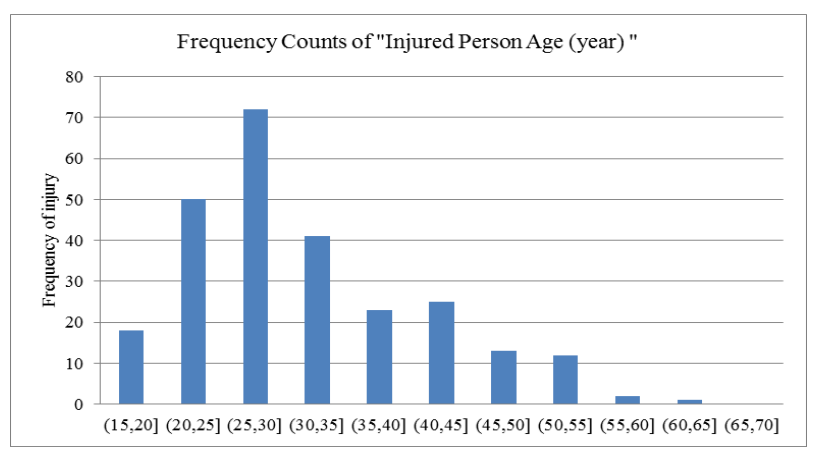

Fig. 10. Personal injury incidents by seafarer's age (years).

According to personal injury data analysis, factors such as seafarers' individual factors (age, nationality, rank, time on board, time in company, etc.), the vessel type, the operations on board, the places on board and the locations of the vessel along voyage all contribute to personal injury incidents.

\section{A. Chi-Square Test}

In order to establish the relationship between the factors and the injury categories, Chi-square test was applied to determine factors bearing strong correlation with personal injury incident. The standard level of significance of $0.05(\mathrm{P}<$ 0.05 ) was used to justify a claim of a statistically significant effect. By comparing the counts of personal injury with other factors (injured seafarer's nationality, age, time on board, time in company, rank and time in rank; vessel's type and age; team involved in incident, location along voyage, place on board vessel, type of operations, and trading region) by Chi-square test, the results are shown in Table I.

According to Table I, the factors that have strong and significant relationship with personal injury occurrences are nationality, length of time on board vessel, location along voyage, trading region, and type of on-board operations.

TABLE I: RESUlTS OF CHI-SQUARE TEST

\begin{tabular}{ll}
\hline \multicolumn{1}{c}{ Factor } & \multicolumn{1}{c}{ P-value } \\
\hline Injured seafarer's nationality & $0.0193^{*}$ \\
Injured seafarer's age & 0.8801 \\
Injured seafarer's time on board (TOB) & $0.0438^{*}$ \\
Injured seafarer's time in company (TIC) & 0.0590 \\
Injured seafarer's rank & 0.7056 \\
Injured seafarer's time in rank (TIR) & 0.2108 \\
Vessel's type & 0.0897 \\
Vessel's age & 0.9365 \\
Team involved in incident & 0.6595 \\
Location along voyage & $0.0082^{*}$ \\
Place on board vessel & 0.6064 \\
Type of operations & $0.0489^{*}$ \\
Trading region & $0.0046^{*}$ \\
\hline
\end{tabular}

\section{CONTRIBUTORY FACTORS AND RISK CONTROL MEASURES}

\section{A. Contributory Factor Analysis}

The contributory factors include direct factors, indirect factors and the root factors. Direct contributory factors are acts or conditions that directly relate to the incident, including unsafe acts and unsafe conditions. Unsafe acts (UA) and unsafe conditions (UC) made up 66\% and 34\%, respectively, with the distribution of various factors shown in Fig. 11. For unsafe acts, especially UA-Improper method/ Procedure adopted, UA-Improper lifting or position on the job were readily associated with personal injury incidents. Unsafe conditions, especially UC-Workspace restrictions, UC-Inadequate guards or barriers conditions also readily resulted in personal injury incidents.

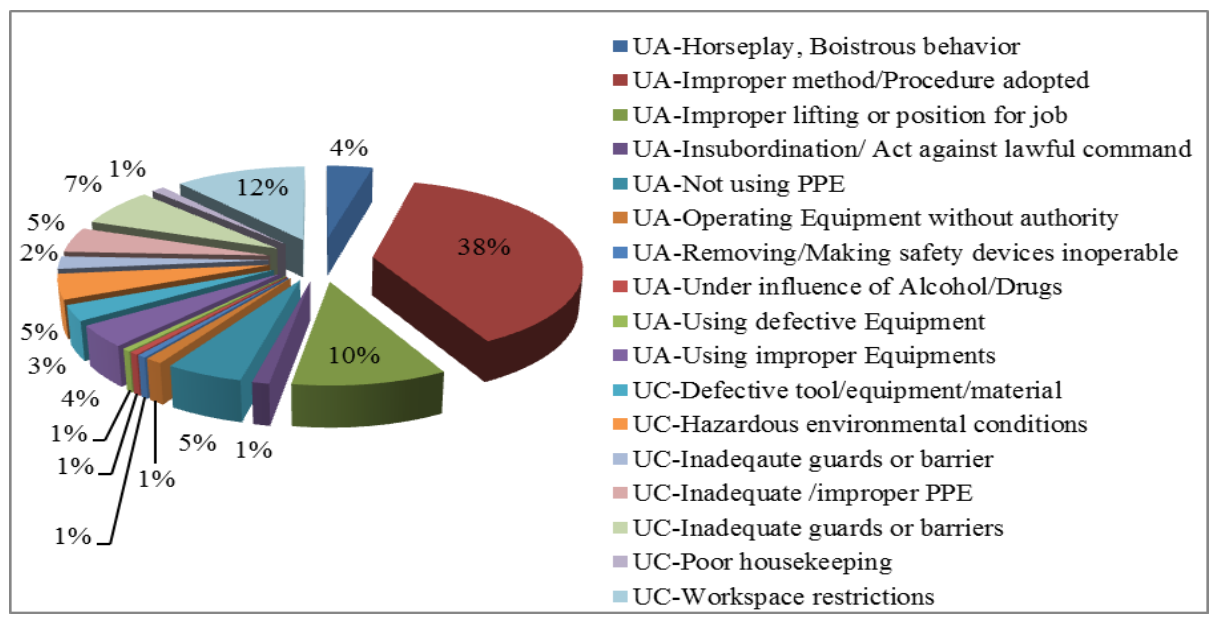

Fig. 11. Direct contributory factors for personal injury incidents.

The indirect factors of personal injuries include human factors (HF) and job factors (JF). The human factors such as inattention and haste are identified to be indirectly contributing to a large number of personal injury incidents, which made up $88 \%$ of all incidents. And $42 \%$ of personal injury incidents can be attributed to HF-Inattention, as shown in Fig. 12. 


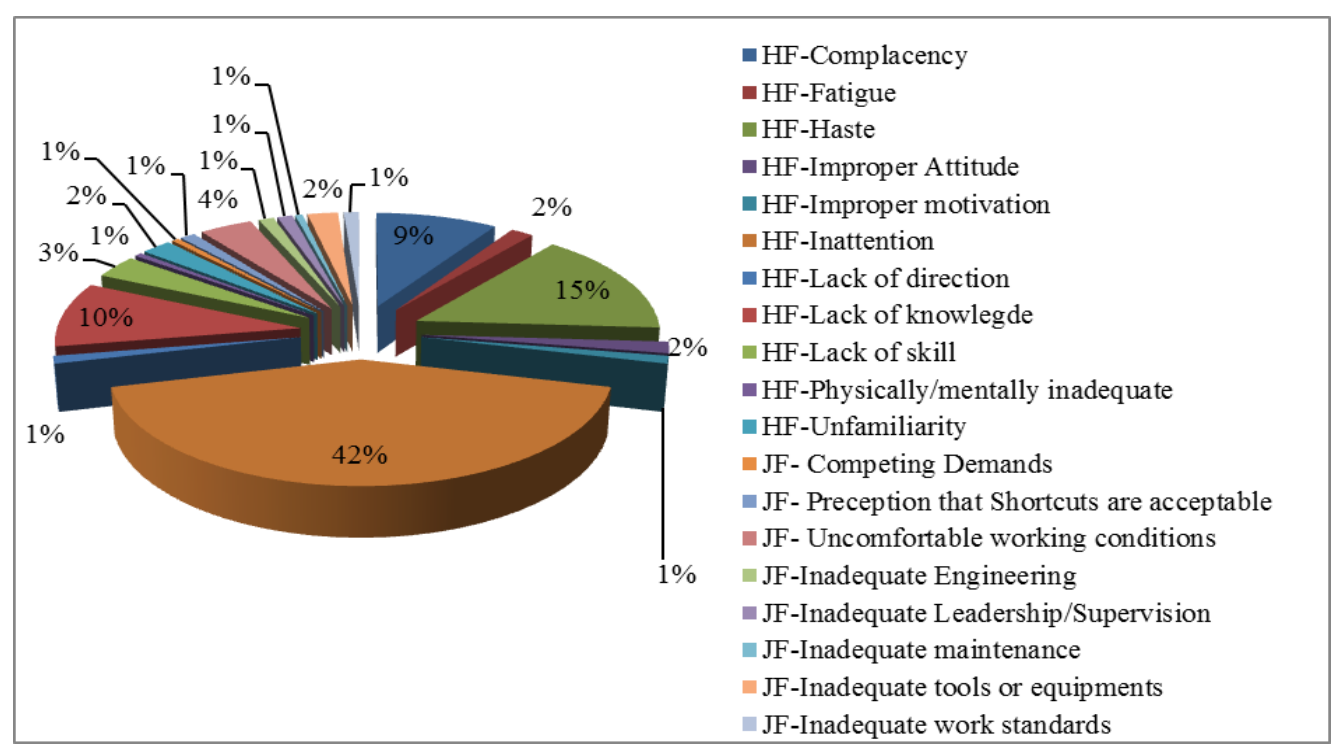

Fig. 12. Indirect contributory factors for personal injury.

Root Factor Analysis seeks to identify the origin of a problem. The root contributory factor of personal injury incidents mainly include communication, defenses, design, error enforcing conditions, hardware, housekeeping, incompatible goals, maintenance management, organization, procedure and training. Among these factors, incompatible procedure, error enforcing conditions and defenses are the top three predominant factors associated with personal injury incidents.

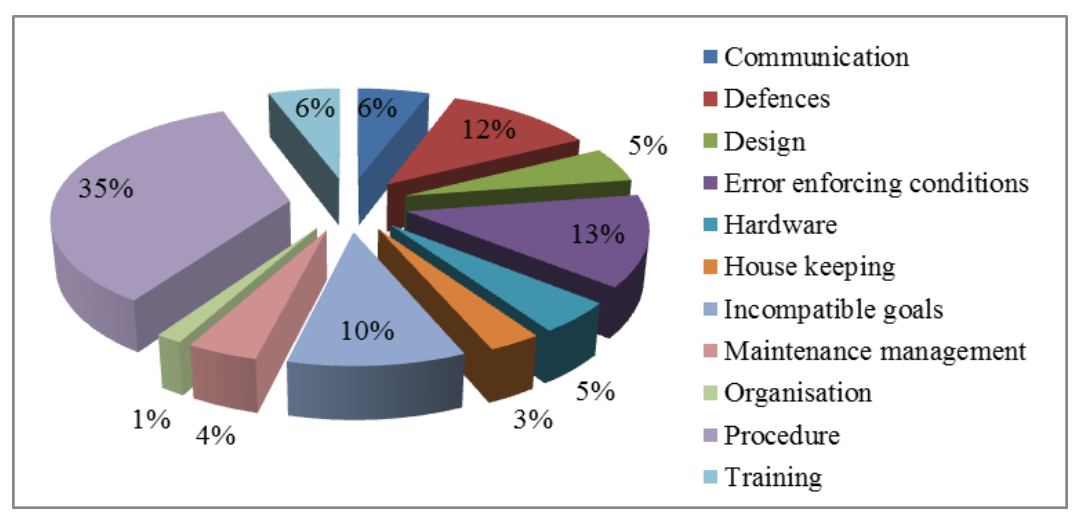

Fig. 13. Root contributory factors for personal injury incidents.

\section{A. Risk Control Measures}

It is imperative to ensure all on-board personnel are wearing adequate and appropriate personal protection equipment (PPE). Clear and concise instructions / orders are to be issued to staff on the safe working methods and use of permit to the work systems in carrying out certain identified tasks. Prior to commencement of work, appropriate barriers and defenses shall be clearly established and be understood in order to prevent incidents/ injuries from occurring. To avoid high-potential incidents and to stop the incidents escalating to incidents/ injuries, some measures can be carried out to improve the safety on-board, as given in the following.

- Training and guiding crew members to follow best practices, company procedures and safe operations;

- Follow procedures in the manuals, industry best practice guidelines and publications;

- Always use appropriate PPE and ensure shipmates are doing the same;

- Do not take short cuts;

- Stop crew members who are working in an unsafe manner or environment;

- Communicate effectively with staff for proper execution of tasks;

- Senior shipboard management is to lead in following safe practices;

- Assess risks effectively, such as tool box meetings, detailed risk assessments;

- Shipboard management teams need to drive safe behavior and proper housekeeping through regular supervisory rounds;

- Proper supervision is carried out during the task;

- Remain alert to other operations going on nearby to self;

- Never take short cuts that could put own or other people's safety at risk;

- Make sure the equipment has been checked thoroughly before it is used for the first time;

- Must be particularly careful when the motion of the vessel is being adversely affected by weather conditions;

- Do not use a chemical without familiarizing oneself with the hazards; 
- Avoid any spillage of oil and chemicals by good housekeeping and operating practices;

- Time for work and time for rest should be strictly followed;

- Share opinions with other crew members; and

- Improve the facilities and layouts of the work place on-board if possible, and so on.

\section{CONCLUSIONS}

In this research, personal injury incidents recorded by an international tanker shipping company were analyzed, which showed that personal injury incidents are more likely happen in the engine room and main deck, in the first month of the voyage, and when seafarers are doing general deck maintenance operation. The contributory factors to personal injury incidents were analyzed, including direct factors, indirect factors, and root factors. For the direct factors, unsafe act by ways of improper method/ procedure and improper lifting or position were the prime contributors to personal injury incident occurrences while unsafe condition in terms of workspace restrictions and inadequate guards or barriers were key contributors to personal injury incidents. Human factors were identified to contribute indirectly to a large number of personal injuries. For the root factors, incompatible procedure, error enforcing conditions and defenses were the key contributors to personal injuries. Risk control measures are proposed, which can be of value-add managerial contributions to the safety of tanker shipping industry.

\section{ACKNOWLEDGMENTS}

This paper was derived from a research project funded by Singapore Maritime Institute (SMI) to which the authors express their gratitude.

\section{REFERENCES}

[1] Review of maritime transport, United Nations Conference on trade and Development, 2015.

[2] S. Kivimaa, A. Rantanen, T. Nyman, D. Owen, T. Garner, and B. Davies, "Ship motions, vibration and noise influence on crew performance and well-being studies in FAROS project," in Proc. Transport Research Arena (TRA) 5th Conference: Transport Solutions from Research to Deployment, 2014.

[3] M. Oldenburg, X. Baur, and C. Schlaich, "Occupational risks and challenges of seafaring," Journal of occupational health, vol. 52, no. 5 , pp. 249-256, 2010.

[4] M. Bloor, M. Thomas, and T. Lane, "Health risks in the global shipping industry: an overview," Health, Risk \& Society, vol. 2, no. 3, pp. 329-340, 2000
[5] A. Collins, V. Matthews, and R. McNamara, "Fatigue, health, injury among seafarers, workers on offshore installations: A review," Seafarers International Research Centre, 2000.

[6] A. P. Smith, A. Lane, M. J. Bloor, P. H. Allen, A. Burke, and N. Ellis, "Fatigue offshore: Phase 2, the short sea and coastal shipping industry," Seafarers International Research Centre, Cardiff University, U. K., 2003.

[7] B. M. Haward, C. H. Lewis, and M. J. Griffin, "Motions and crew responses on an offshore oil production and storage vessel," Applied Ergonomics, vol. 40, no. 5, pp. 904-914, 2009.

[8] P. Allen, E. Wadsworth, and A. Smith, "Seafarers' fatigue: a review of the recent literature," Int Marit Health, vol. 59, pp. 81-92, 2009.

[9] B. Wellens, "Collisions and collision risk awareness at sea: Data from a variety of seafarers," Centre for Occupational and Health Psychology, Cardiff University, U. K., pp. 573-577, 2005.

[10] O. C. Jensen, J. Sørensen, M. Canals, Y. P. Hu, N. Nikolic, and M. Thomas, "Incidence of self-reported occupational injuries in seafaring - An international study," Occupational Medicine, vol. 54, no. 8, pp. 548-555, 2004.

[11] B. E. Moen, R. Nilsson, R. Nordlinder, S. Ovreb $\varnothing$, K. Bleie et al., "Assessment of exposure to polycyclic aromatic hydrocarbons in engine rooms by measurement of urinary 1-hydroxypyrene," Occupational and Environmental Medicine, vol. 53, no. 10, pp 692-696, 1996.

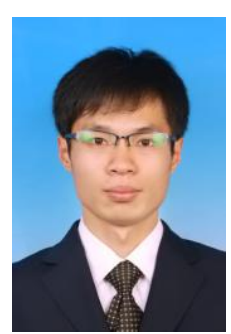

Qingji Zhou received the Ph.D. in ocean and naval engineering from Tianjin University, China. He had done his post-doctoral research for two years after graduation in China, and his current position is Research Fellow in Maritime Institute @NTU, Nanyang Technological University in Singapore. His areas of research interest are offshore engineering, maritime risk analysis, etc.

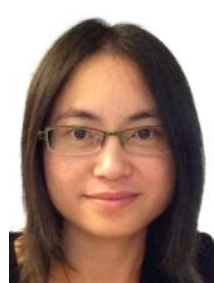

Hong Xu received her bachelor's degree in psychology from Peking University, master and Ph.D degrees in statistics and psychology from University of Chicago respectively. She is currently an assistant professor of psychology in the School of Humanities and Social Sciences at .Nanyang Technological University since 2009. Her area of expertise is in vision perception. Her research interest is to study visual perception by psychophysical experiments and electrophysiological/ neural imaging studies; and further model the neural network system with recorded neural activities.

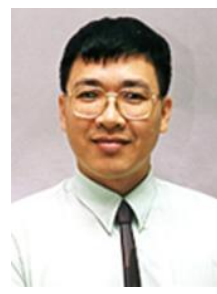

Yiik Diew Wong is a faculty member at Nanyang Technological University since 1991. His R\&D interests are in urban mobility which covers road user behavior and road transport infrastructure. He has also undertaken research in freight transport; maritime safety \& security; and maritime manpower developments. Dr Wong is presently Director of Centre for Infrastructure Systems (CIS), and Deputy Director of Transport Research Centre (TRC@NTU). 